\title{
Photoconductive and ellipsometric studies of spray pyrolysed CdS thin films
}

\author{
A G VALYOMANA, SUNNY MATHEW, K P VIJAYAKUMAR \\ and C PURUSHOTHAMAN \\ Department of Phýsics, Cochin University of Science and Technology, Kochi 682 022, India \\ MS received 12 June 1991; revised 27 April 1992
}

\begin{abstract}
The influence of annealing temperature on photoconductivity of spray pyrolysed $\mathrm{CdS}$ films has been investigated. The annealing of films at $373 \mathrm{~K}$ resulted in maximum photoconductivity. The photoconductivity at all wavelengths was found to decrease with increase of annealing temperature and became a minimum at $473 \mathrm{~K}$. For films annealed at or above $523 \mathrm{~K}$, the photoconductivity for wavelengths $\geqslant 560 \mathrm{~nm}$ decreased considerably. The results are discussed with the help of ellipsometric data, visible and IR spectra of these samples. Also the variation in photoconductivity of these samples were studied during heating to analyse the effect of trapping.
\end{abstract}

Keywords. Spray pyrolysis; CdS; photoconductivity; ellipsometry.

\section{Introduction}

The investigation of electrical transport in chemically sprayed CdS film is of current interest because of the application of material in the fabrication of photovoltaic cells. The remarkable photoconductive and luminescent properties of this material along with its large bandgap of $\sim 2.4 \mathrm{eV}$ make it promising for the study of carrier trapping effects.

There are several published works on different properties of CdS films prepared using techniques like sputtering (Takeuchi et al 1976; Clarke and Greene 1981; Viktor et al 1983), evaporation (Shibata 1977; Bhide et al 1978), electrolytic deposition (Krupa and Wrzesinska 1978), sintering (Jakimavicius et al 1974) and screen printing (Vojdani et al 1973). But studies on properties of the films prepared using spray pyrolysis technique are quite a few in number (Wu and Bube 1974; Bougnot et al 1976; Gupta et al 1978). Wu and Bube (1974) have shown that photoconductivity of solution-sprayed film was caused by an increase in electron mobility using photothermoelectric analysis. Although Bougnot et al (1976) and Gupta et al (1978) studied electrical properties of CdS films prepared from solutions having various percentages of thiourea, the variation of photocurrent with annealing temperatures of these films has not yet been reported and this is analysed here.

In the present work, two quantities, viz. photoconductivity and ellipsometric measurements, have been used. The photoconductivity technique gives direct information about the effect of traps in semiconducting materials. The second technique viz. ellipsometry is a sensitive and non-destructive one which has been used for analysing the structural variations in different layers of film taking place due to annealing (Vedam et al 1985; Vijayakumar 1991). 


\section{Experimental details}

The CdS thin films were prepared by spraying aqueous solution ( $0.2 \mathrm{M})$ of cadmium chloride and thiourea (Valyomana et al 1988; Vijayakumar 1991) on glass substrate kept at $573 \mathrm{~K}$. The atomization of the chemical solution into a spray of fine droplets is effected by the spray nozzle with the help of compressed air as carrier gas. The spray rate was kept at $28 \mathrm{~cm}^{-3} / \mathrm{min}$. Film thickness $(\sim 300 \mathrm{~nm})$ was measured using ellipsometry.

Annealing of the samples was carried out in air for $30 \mathrm{~min}$ in a chamber using different temperatures in the range $373-573 \mathrm{~K}$. The heating/cooling rate in all cases of annealing was $4 \mathrm{~K} / \mathrm{min}$.

Electrical contacts to the CdS films were made through aluminium electrodes (thickness $\sim 200 \mathrm{~nm}$ ) using vacuum evaporation technique at a pressure of $10^{-5}$ torr. The set-up used for photoconductivity measurement consists of a quartz tungsten halogen lamp (Oriel No. 7340) and a double monochromator (Oriel No. 7240). The area of illumination on the surface was always $0.6 \mathrm{~cm}^{2}$. After setting the specimen, $9 \mathrm{~V}$ voltage was applied and the photocurrent measured in the wavelength range of 400 to $640 \mathrm{~nm}$ in vacuum. The films were then heated in the temperature range from room temperature to $424 \mathrm{~K}$. Sample temperatures were measured by a chromel-alumel thermocouple. Further details of the photoconductivity measurements have been reported elsewhere (Valyomana et al 1990).

The light source in the ellipsometric set-up was a tungsten lamp. In the present work nine analyzer azimuths were selected for measuring intensity of reflected light and thus 84 values of $\psi$ and $\Delta$ were obtained for each angle of incidence (Azzam and Bashara 1977). The average of these values was taken so as to keep the error in ellipsometric parameters to the minimum. The details of theory and experimental set-up of ellipsometry were published elsewhere (Vijayakumar 1991).

The transmission spectra of the annealed samples were recorded using a Beckmann infrared spectrophotometer and the absorption spectra in the visible region were charted with the help of a U-3410 Hitachi spectrophotometer.

\section{Results and discussion}

The dependence of photoconductivity on annealing temperature of CdS films is shown in figure 1. It was observed that the photoconductivity was maximum in films annealed at $373 \mathrm{~K}$. This fact was clarified by taking into consideration the absorption spectra of the films (figure 2) in the visible region $400-700 \mathrm{~nm}$. It was seen here that the absorption was higher in the samples annealed at $373 \mathrm{~K}$. Another observation was that the photoconductivity was found to decrease with increase of annealing temperature and became a minimum at $473 \mathrm{~K}$. It should be noted here that the higher conductivity values observed in films annealed at $373 \mathrm{~K}$ was probably due to generation of higher number of carriers and consequently, this carrier generation got reduced considerably when films were annealed at $473 \mathrm{~K}$ (Valyomana et al 1990). The transmission spectra of the samples annealed at $473 \mathrm{~K}$ in the near IR region (given as inset in figure 2) explain why these films have lowest photoconductivity. This gave an idea about the position of traps in the bandgap. The samples annealed at $473 \mathrm{~K}$ showed a broad absorption in the region 3250 to $2760 \mathrm{~nm}$ which corresponded to an energy level lying $\sim 0.4 \mathrm{eV}$ to $0.45 \mathrm{eV}$ above the valence band. Since 


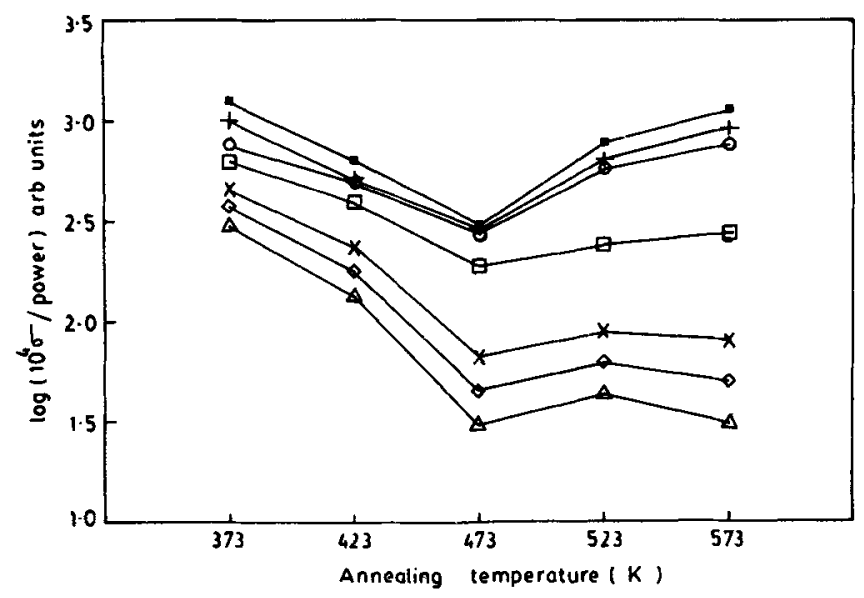

Figure 1. Plot of $\log \left(10^{4} \sigma /\right.$ power $)$ against annealing temperature for different wavelengths.

(日) $400 \mathrm{~nm} ;(+) 440 \mathrm{~nm}$; (O) $480 \mathrm{~nm}$; (D) $520 \mathrm{~nm}$; ( $) 560 \mathrm{~nm} ;(\diamond) 600 \mathrm{~nm} ;(\triangle) 640 \mathrm{~nm}$.

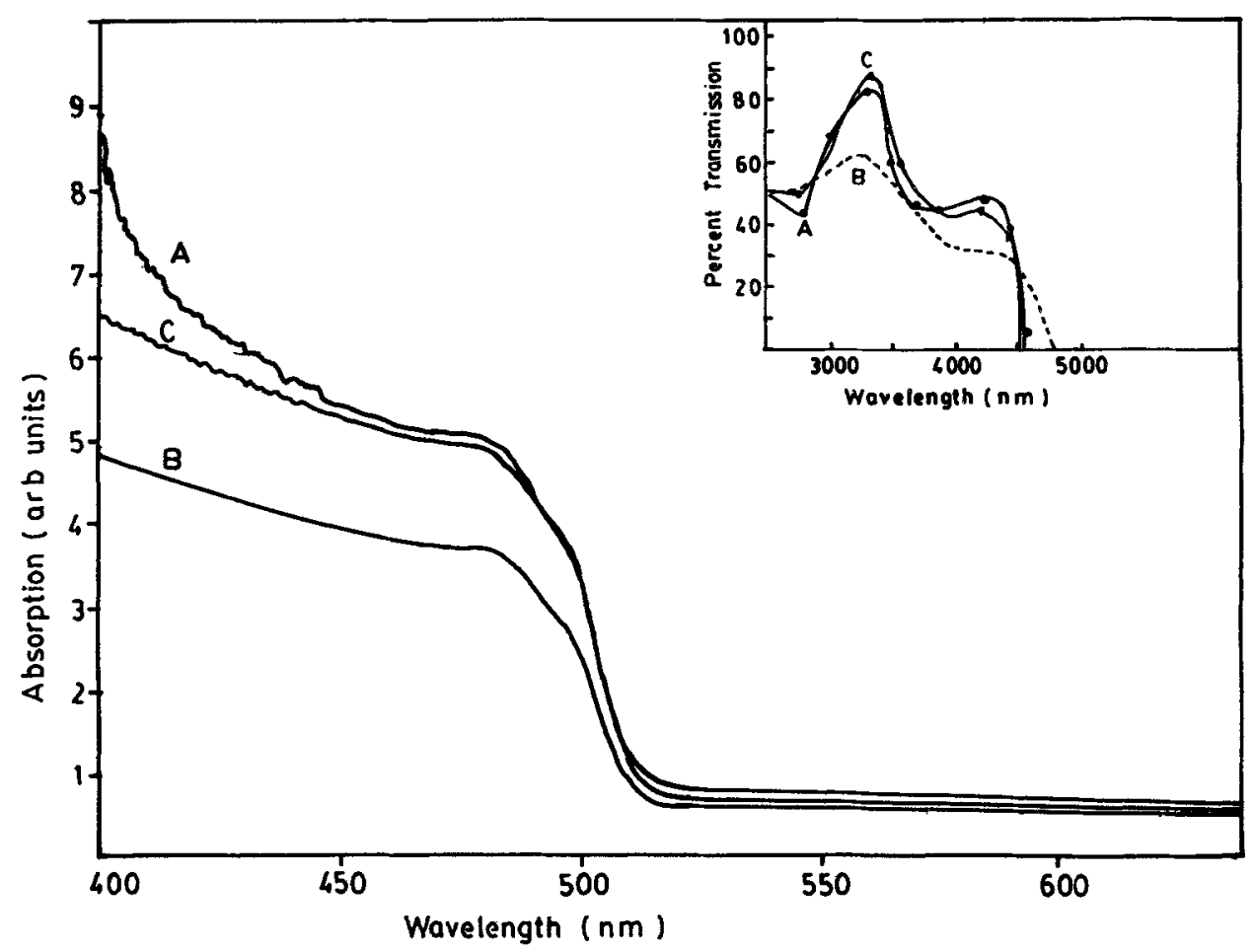

Figure 2. Absorption spectra of CdS films annealed at different temperatures. (A) $373 \mathrm{~K}$; (B) $473 \mathrm{~K}$; (C) $573 \mathrm{~K}$. The inset gives transmission spectra of these films annealed at different temperatures (A) $373 \mathrm{~K}$; (B) $473 \mathrm{~K}$; (C) $573 \mathrm{~K}$.

the bandgap of CdS was $\sim 2 \cdot 4 \mathrm{eV}$, this indicated the existence of a trap level at a depth of $\sim 2 \mathrm{eV}$ below the conduction band. The results of studies on $n$-type CdS crystals also support this view (Edwin Siu and Andreas 1986). Obviously, the decrease in photoconductivity at $473 \mathrm{~K}$ as observed in figure 1 was caused by trapping of 
minority carriers at the energy level of $\sim 2 \mathrm{eV}$. These results were confirmed further from the absorption spectra (figure 2) which showed that these samples had minimum absorption.

It was evident from figure 1 that the photoconductivity of CdS films annealed above $473 \mathrm{~K}$ had a pronounced effect on the wavelengths in the range $400-600 \mathrm{~nm}$. The photoconductivity at $400 \mathrm{~nm}$ which was mainly due to the carriers excited to the conduction band from valence band showed a small increase as annealing temperature increased above $473 \mathrm{~K}$. This could have been due to reduction in traps in the films, and this in turn, led to an increase in the number of carriers of higher energy $\sim 3 \mathrm{eV}$ (energy corresponded to the wavelength of light centred at $400 \mathrm{~nm}$ ).

Annealing affected drastically the conductivity at longer wavelengths i.e. the photoconductivity decreased abruptly at wavelength $\lambda \geqslant 600 \mathrm{~nm}$ for films annealed at or above $523 \mathrm{~K}$. This implied that the number of carriers of low activation energy had an influence on the annealing temperature. This was quite clear from the examination of the ellipsometric studies.

Figure 3 gives the results of ellipsometric studies of these samples. In this analysis, it was found that the refractive index of the film was not uniform throughout the thickness of the film. In the case of films annealed at or above $523 \mathrm{~K}$, it was observed that there was a top layer (of thickness $135 \mathrm{~nm}$ ) having real part of refractive index $n=2.62$ and imaginary part of refractive index $k=0.8$ and the layer below this was having normal refractive index $n=2 \cdot 3$ and $k=0 \cdot 1$. So a model of air/CdS layer with $n=2.62$ and $k=0.8 /$ normal CdS was exactly suitable for films annealed at or above $523 \mathrm{~K}$ and this is indicated in figure 3 . Here the top defective layer was so thick that the light waves could not reach the glass/CdS interface at the bottom. On the other hand, similar analysis of films annealed at $473 \mathrm{~K}$ revealed that it also had a defective top layer ( $n=2 \cdot 25$ and $k=0 \cdot 285$ ). But its thickness was merely $70 \mathrm{~nm}$ and hence light

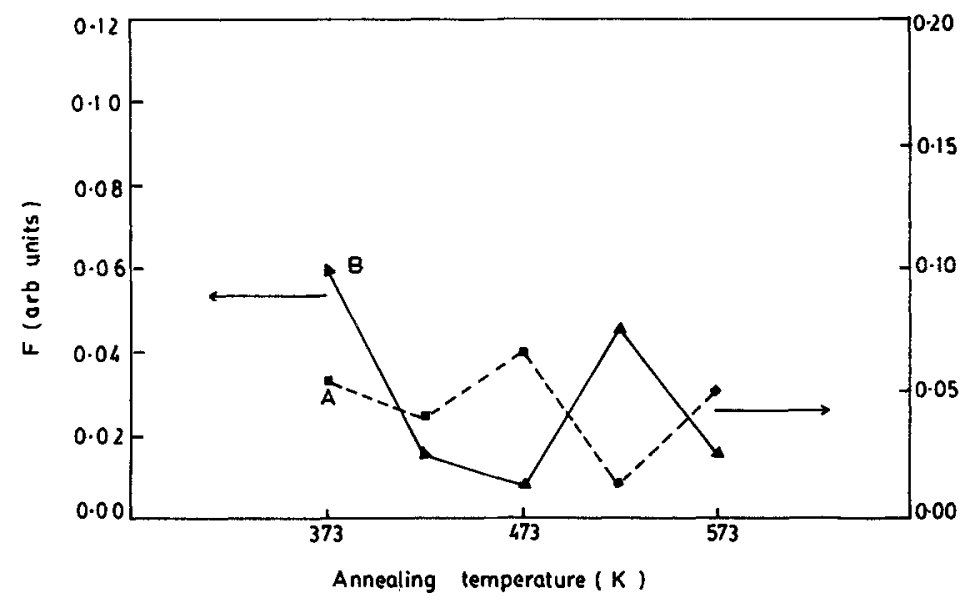

Figure 3. Variation of $F$-factor with annealing temperature. (A) A model of air/CdS layer with $n=2.62$ and $k=0.8 /$ normal CdS with $n=2 \cdot 3$ and $k=0 \cdot 1$. The minimum in $F$-value at $523 \mathrm{~K}$ indicates that this model is best suited for the film annealed at that temperature. (B) A model of air/CdS layer with $n=2.25$ and $k=0.285 /$ normal CdS with $n=2.3$ and $k=0.1 /$ glass. The minimum in $F$-value at $473 \mathrm{~K}$ indicates that this model is best suited for the film annealed at that temperature. The wavelength of light used in both these cases is $646 \mathrm{~nm}$. 
waves could readily reach the $\mathrm{CdS} /$ glass interface also. Here the best suitable model was air/CdS with $n=2.25$ and $k=0.285 /$ normal $\mathrm{CdS} /$ glass and this is also indicated in figure 3.

A light beam of energy lower than the bandgap was naturally absorbed at a greater depth compared to light having energy greater than the bandgap. Considering the configuration of electrodes in the present case, one can see that the carriers excited by the photons of longer wavelengths have to cross the thick defective layer present at the top of the samples annealed at or above $523 \mathrm{~K}$ to reach the electrode. This will result in a greater probability of trapping of carriers by the traps/defects present in the top layer as well as in the interface between the two layers. Probably this may be the reason for the decrease in photoconductivity at these wavelengths for films annealed at or above $523 \mathrm{~K}$.

The authors have also observed the variation in photoconductivity of the samples annealed at 373,473 and $573 \mathrm{~K}$ by keeping the samples at different temperatures in the range 303-424 $\mathrm{K}$ and the results are depicted in figures 4, 5 and 6 respectively. Since not much influence was observed in photoconductivity with temperature at all wavelengths as indicated in figure 4 , it was clear that trapping of carriers did not occur in CdS films annealed at $373 \mathrm{~K}$. But it can be seen from figure 5 that the photoconductivity at all wavelengths increased with temperature due to the release of trapped carriers. Hence in the case of samples annealed at $473 \mathrm{~K}$, trapping occurred for the carriers generated by photons of all wavelengths (i.e. from 400 to $640 \mathrm{~nm}$ ). In other words, the traps, at a depth of $\sim 2 \mathrm{eV}$ from the conduction band, which were found to be present in these samples, might be available in more or less uniform rate throughout the thickness of these samples. The photoconductivity of the samples annealed at $573 \mathrm{~K}$ (figure 6) did not show any variation with temperature for excitation with wavelengths up to $480 \mathrm{~nm}$. This indicated that no trapping occurred for these carriers. But for these samples, there was considerable rise in the photoconductivity at higher wavelengths as temperature of the samples was increased. This supported the observation of ellipsometric studies in which it was found that a structurally

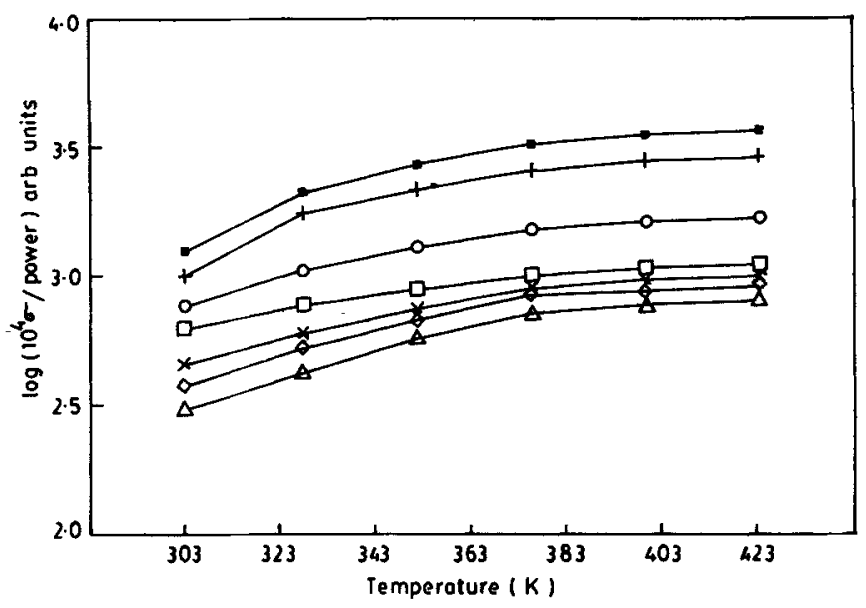

Figure 4. Plot of $\log \left(10^{4} \sigma /\right.$ power) against temperature of CdS films annealed at $373 \mathrm{~K}$ for different wavelengths (a) $400 \mathrm{~nm}$; (+) $440 \mathrm{~nm}$; (O) $480 \mathrm{~nm}$; ( $\square$ ) $520 \mathrm{~nm}$; ( $\times$ ) $560 \mathrm{~nm}$; (১) $600 \mathrm{~nm} ;(\triangle) 640 \mathrm{~nm}$. 


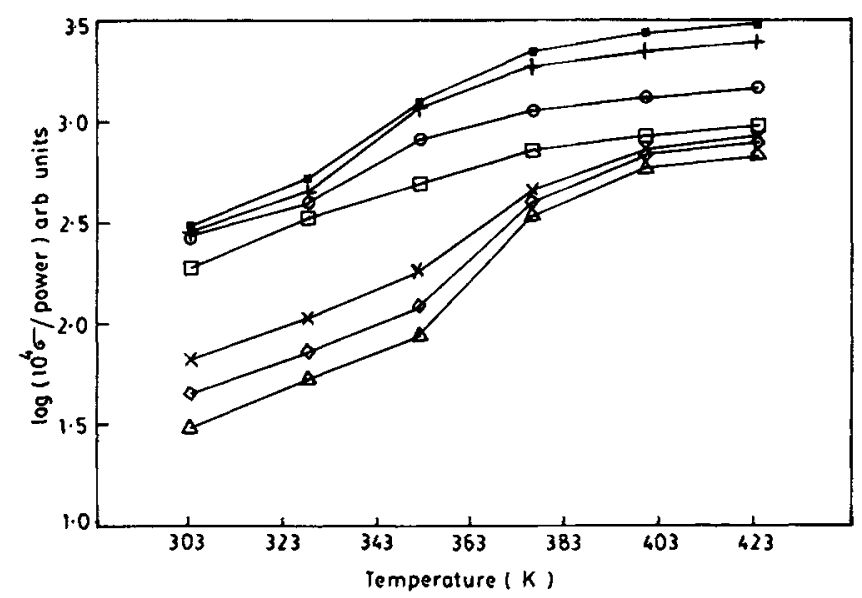

Figure 5. Plot of $\log \left(10^{4} \sigma /\right.$ power $)$ against temperature of CdS films annealed at $473 \mathrm{~K}$ for different wavelengths. (a) $400 \mathrm{~nm}$; (+) $440 \mathrm{~nm}$; (O) $480 \mathrm{~nm}$; ( $\square) 520 \mathrm{~nm}$; ( $\times$ ) $560 \mathrm{~nm}$; $(\diamond) 600 \mathrm{~nm} ;(\triangle) 640 \mathrm{~nm}$.

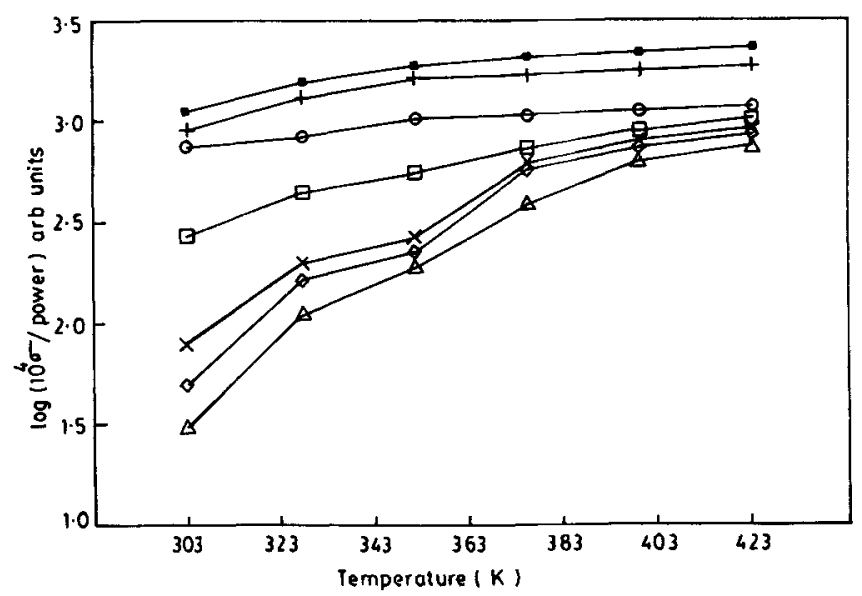

Figure 6. Plot of $\log \left(10^{4} \sigma /\right.$ power $)$ against temperature of CdS films annealed at $573 \mathrm{~K}$ for different wavelengths. (a) $400 \mathrm{~nm}$; (+) $440 \mathrm{~nm}$; (O) $480 \mathrm{~nm}$; ( $\square) 520 \mathrm{~nm}$; (x) $560 \mathrm{~nm}$; $(\diamond) 600 \mathrm{~nm} ;(\triangle) 640 \mathrm{~nm}$.

defective layer having thickness $\sim 135 \mathrm{~nm}$ might be present on the top of these samples.

\section{Conclusions}

Thin films of $\mathrm{CdS}$ were prepared by spray pyrolysis. The films annealed at $373 \mathrm{~K}$ were found to have maximum photoconductivity. This was due to higher absorption as revealed from the absorption spectra. Since the trapping of minority carriers occurred at an energy level $\sim 2 \mathrm{eV}$ below the conduction band, minimum photocurrent was obtained for films annealed at $473 \mathrm{~K}$. The increase in photoconductivity of the films 
annealed above $473 \mathrm{~K}$ at $400 \mathrm{~nm}$ was associated with the enhancement of the number of carriers having energy $\sim 3 \mathrm{eV}$. The reason for the decrease in photoconductivity at $\lambda \geqslant 600 \mathrm{~nm}$ for films annealed above $523 \mathrm{~K}$ has been confirmed from ellipsometric analysis. The effect of heating on the photoconductivity of annealed samples from $303 \mathrm{~K}$ to $424 \mathrm{~K}$ showed that the trapping of carriers did not occur in films annealed at $373 \mathrm{~K}$.

\section{Acknowledgements}

One of the authors (AGV) wishes to thank the Council of Scientific and Industrial Research, New Delhi for providing the fellowship. Financial assistance from the Department of Atomic Energy is also gratefully acknowledged.

\section{References}

Azzam R M A and Bashara N M 1977 in Ellipsometry and polarized light (Amsterdam: North Holland) p. 256

Bhide V G, Jatar S and Rastogi A C 1978 Pramana-J. Phys. 10477

Bougnot J, Perotin M, Maruechi J, Sirkis M and Savelli M 1976 in Proc. 12th IEEE photovoltaic specialists conference, Baton Rouge, USA, p. 519

Clarke J R and Greene J E 1981 J. Vac. Sci. \& Technol. 18382

Edwin Siu K M and Andreas M 1986 Phys. Rev. B34 7222

Gupta B K, Agnihotri O P and Ahmar Raza 1978 Thin Solid Films 48153

Jakimavicius J A, Alisauskas A V, Douba A U and Sirvaitis A I 1974 Sov. Phys. Collect. 1485

Krupa R and Wrzesinska A 1978 Acta Phys. Pol. $\mathbf{A 5 3} 675$

Shibata H 1977 J. Vac. Soc. Japan 20358

Takeuchi M, Sakagawa Y and Nagasaka H 1976 Thin Solid Films 3389

Valyomana A G, Vijayakumar K P and Purushothaman C 1988 in Proc. Solid State Phys. Symp., Bhopal, India, p. 336

Valyomana A G, Vijayakumar K P and Purushothaman C 1990 J. Mater. Sci. Lett. 91025

Vedam K, McMarr P J and Narayanan J 1985 Appl. Phys. Lett. 47339

Vijayakumar K P 1991 Bull. Mater. Sci. 1457

Viktor P A, Zotov V V, Korepanov S A and Serdyuk V V 1983 Inorg. Mater. 19155

Vojdani S, Sharifuai A and Doroudian M 1973 Electron. Lett. 9128

Wu C and Bube R H 1974 J. Appl. Phys. 45648 